\title{
Perbandingan Kinerja Pelayanan Self Check-In dengan Check-In Konvensional untuk Maskapai Citilink dan Airasia Di Bandar Udara Internasional Surabaya
}

\author{
Muhammad Irfan Ardiansyah dan Ervina Ahyudanari \\ Departemen Teknik Sipil, Fakultas Teknik Sipil dan Perencanaan, Institut Teknologi Sepuluh \\ Nopember (ITS) \\ e-mail: ervina@ce.its.ac.id
}

\begin{abstract}
Abstrak-Dengan perkembangan teknologi yang pesat, Terminal Bandar Udara Internasional Juanda Surabaya sudah menggunakan sistem self check-in.. Sistem self check-in adalah suatu fasilitas/tempat yang berfungsi untuk menyelesaikan berbagai prosedur dan persyaratan keamanan dan pelayanan yang menggunakan suatu mesin. Sistem ini sudah diterapkan di beberapa negara seperti Australia, Amerika Serikat, dan negara-negara di benua Eropa. Sistem self check-in ini memiliki prosedur yang sangat mudah, dengan hanya melakukan scan barcode atau memasukan nomor e-ticket, kemudian memilih seat dan print boarding pass. Dikarenakan prosedur check-in yang mudah, terdapat $83 \%$ penumpang lebih memilih sistem self check-in (IATA Global Passenger Survey, 2014). Studi ini akan membandingkan efektivitas penggunaan self check-in dengan check-in konvensional yang disesuaikan dengan Peraturan Direktur Jenderal Perhubungan Udara Nomor : SKEP/77/VI/2005,dan standar Level of Service IATA. Perbandingan penggunaan self check-in dan checkin konvensional dilakukan dengan pentahapan awal adalah pengumpulan data waktu antar kedatangan penumpang di kedua tipe check-in dan memperkirakan kebutuhan self check-in 10 tahun kedepan. Dalam studi ini hasil yang didapatkan adalah self check-in sangat berpengaruh dalam mengurangi panjang antrian paling sebesar 15 penumpang pada Skenario 1 dan 6 penumpang pada Skenario 2 saat melakukan proses check-in.
\end{abstract}

Kata kunci-Self Check In, Bandar Udara Internasional Juanda, Surabaya, Kinerja Pelayanan.

\section{PENDAHULUAN}

K OTA Surabaya merupakan ibukota Provinsi Jawa Timur, Indonesia, sekaligus kota metropolitan terbesar kedua di Indonesia setelah Jakarta. Sebagai salah satu kota yang paling berkembang di Pulau Jawa, Kota Surabaya mempunyai jumlah penduduk sebanyak 2.943.528 jiwa pada tahun 2015. Menurut PT. Angkasa Pura I (Persero), jumlah penumpang yang menggunakan jasa transportasi udara sebanyak 18.911.256 jiwa pada tahun 2015.

Berdasarkan statistik yg dijelaskan sebelumnya, maka Bandar Udara Internasional Juanda Surabaya merupakan bandara tersibuk kedua di Indonesia yang dikelola oleh PT. Angkasa Pura I (Persero). Untuk saat ini, dengan kemajuan teknologi terdapat 5 jenis sistem check-in yaitu check-in konvensional, online atau web check-in, mobile check-in, self baggage drop dan self check-in. Sistem check-in konvensional yaitu check-in melalui counter yang dilayani oleh sumber daya manusia. Sistem ini masih memiliki kekurangan seperti terdapat antrian yang panjang di Check-in Counter. Untuk online atau web check-in dan mobile check-in memiliki persamaan sistematika check-in, namun terdapat perbedaan yaitu online atau web check-in menggunakan browser dan mobile check-in menggunakan aplikasi yang terdapat pada Google Play Store [1]. Self baggage drop adalah suatu fasilitas/tempat yang berfungsi untuk menyelesaikan berbagai prosedur dalam check-in termasuk baggage drop yang menggunakan mesin.

Sedangkan sistem teknologi self check-in adalah suatu fasilitas/tempat yang berfungsi untuk menyelesaikan berbagai prosedur dan persyaratan keamanan dan pelayanan yang menggunakan suatu mesin tidak termasuk baggage drop. Sistem self check-in ini memiliki prosedur yang sangat mudah, dengan hanya melakukan scan barcode atau memasukan nomor e-ticket, kemudian memilih seat dan print boarding pass. Dikarenakan prosedur check-in yang mudah, terdapat $83 \%$ penumpang lebih memilih sistem self check-in. Untuk saat ini sistem self check-in di Indonesia hanya bisa digunakan untuk para penumpang yang tidak membawa bagasi.

Melihat adanya kondisi tersebut, diharapkan penggunaan sistem self check-in dapat mempersingkat dan mempermudah proses check in . Dengan ini, penyusun ingin mengambil judul studi "Perbandingan Kinerja Pelayanan Self Check In dengan Check In Konvensional untuk Maskapai Citilink dan AirAsia di Bandar Udara Internasional Juanda, Surabaya", untuk mengetahui efektivitas penggunaan self check-in. 


\section{KOTA SURABAYA}

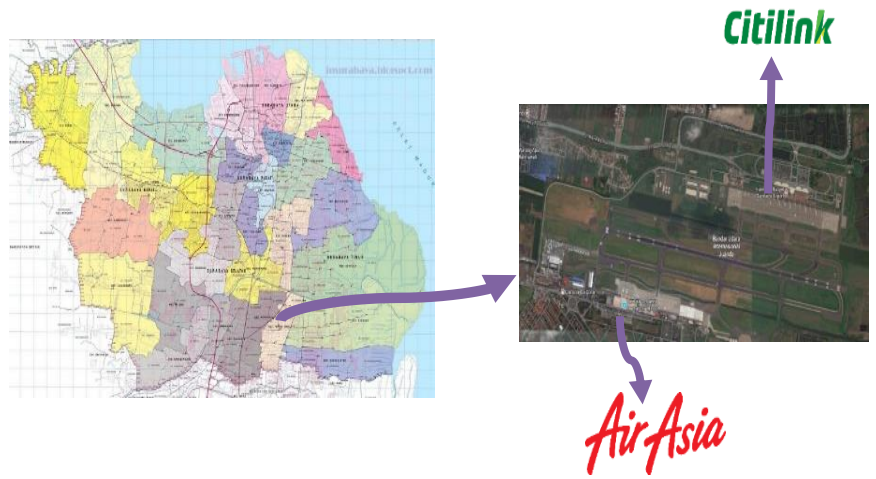

Gambar 1. Lokasi Bandar Udara Internasional Juanda, Surabaya

\section{A. Rumusan Masalah}

Berdasarkan uraian di atas, permasalahan yang akan dibahas dalam studi ini adalah :

1) Bagaimana pola distribusi kedatangan penumpang di Bandar Udara Internasional Juanda Surabaya?

2) Bagaimana antrian yang terjadi apabila dilakukan simulasi berdasarkan hasil survei?

3) Apakah sistem teknologi self check-in lebih efisien dibandingkan dengan sistem check-in konvensional ?

\section{B. Peramalan (Forecasting) Arus Pergerakan Penumpang}

1) Metode Regresi Linier

Persamaan regresi liner arus keberangkatan penumpang untuk Bandara Juanda :

$$
\mathbf{y}=\mathbf{a}+\mathbf{b . x}
$$

Dimana :

$\mathrm{Y}(\mathrm{x})$ = data time series periode $\mathrm{X}$

$\mathrm{x} \quad=$ waktu (hari,minggu,bulan,triwulan,tahun)

$\mathrm{a}, \mathrm{b}=$ bilangan konstan

\section{2) Metode Prosentase Pertumbuhan}

Perhitungan peramalan dengan metode prosentase pertumbuhan ini berdasarkan pada jumlah penumpang pada Bandara Juanda seperti pada rumus berikut :

$\%$ pertumbuhan $=\frac{\text { Epenumpang tahun ke } n-\Sigma \text { penumpang tahun sebelum }(n-1)}{\Sigma \text { penumpang } \text { tahun sebelum }(n-1)} \times 100 \%$

\section{METODOLOGI}

Bagan alir yang dapat dilihat pada Gambar 1 merupakan suatu alur kegiatan studi dalam penyelesaian studi ini. Pengerjaan studi ini, diawali dengan melakukan persiapan yaitu mobilisasi, menyusun rencana survei serta rencana kerja. Kemudian dilanjutkan dengan pengumpulan data primer dan data sekunder. Pengumpulan data primer dilakukan melalui beberapa tahapan yaitu pengamatan check in area di Bandar Udara Internasional Juanda, Surabaya,berupa penggunaan sistem antrian pada check in area, serta perhitungan waktu pelayanan check in dan melakukan data responden melalui Monkey Survey untuk mendapatkan data karakteristik penumpang. Sedangkan pengumpulan data sekunder dapat dilakukan melalui website www.flightstats.com [2] untuk mendapatkan jadwal penerbangan. Setelah survei dan pengumpulan data dilakukan, tahapan selanjutnya adalah mengolah dan menganalisis data-data yang sudah didapatkan. Data - data yang dapat diolah adalah data lama penggunaan self check-in dan counter check-in, data jadwal keberangkatan pesawat dan kapasitas pesawat beserta jumlah penumpang yang digunakan untuk perhitungan tingkat kedatangan, dan panjang antrian dengan menggunakan 2(dua) skenario. Kemudian dilakukan dilakukan 4 pembahasan yaitu proses analisis distribusi kedatangan penumpang [3], service time, panjang antrian dengan menggunakan simulasi dan hasil perbandingan kinerja pelayanan antara self check in dengan check in konvensional, serta peramalan menggunakan metode Regresi Linear dan metode Prosentase Pertumbuhan [4].

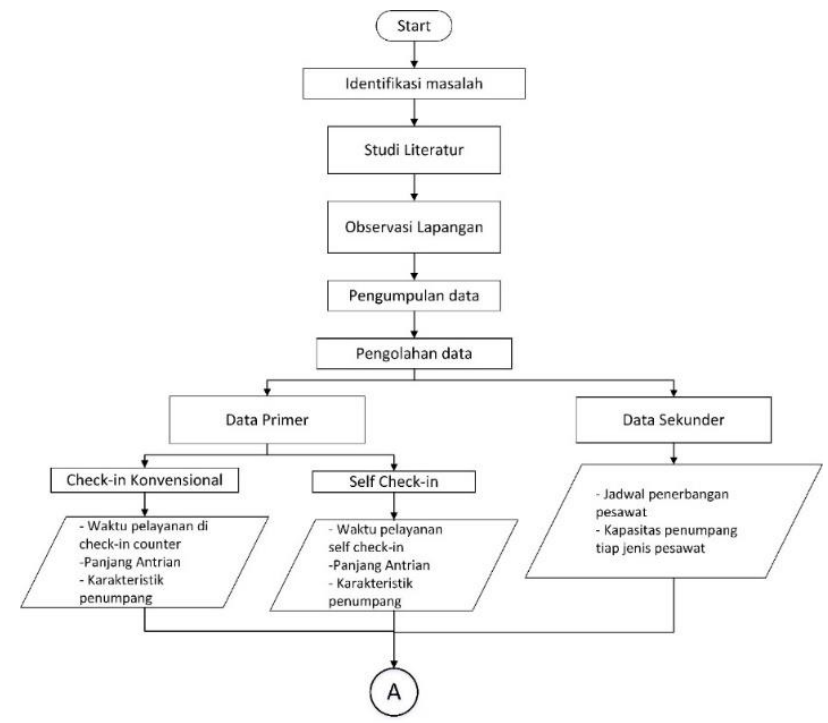

Gambar 2. Bagan Alir Penyelesaian Studi

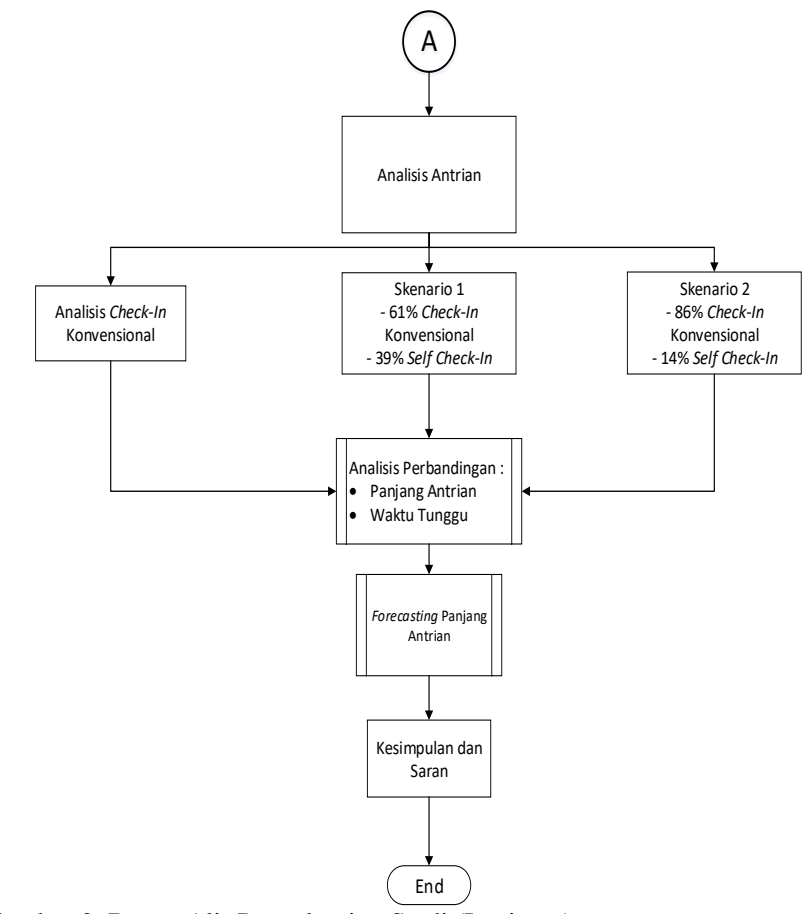

Gambar 2. Bagan Alir Penyelesaian Studi (Lanjutan)

\section{ANALISIS DATA DAN PEMBAHASAN}

\section{A. Data Primer}

Survei dan pengumpulan data, meliputi observasi yang di lakukan di check in area Terminal 1 dan 2 Bandar Udara Internasional Juanda, Surabaya. Survei yang dilakukan adalah pengamatan penggunaan sistem antrian pada check in area, 
serta perhitungan waktu pelayanan check in. Berikut hasil survei waktu pelayanan di self check-in :

Tabel 1

Hasil Survei Waktu Pelayanan

\begin{tabular}{lrrrr}
\hline \hline & \multicolumn{1}{c}{$\begin{array}{l}\text { SAMP } \\
\text { LE 1 }\end{array}$} & $\begin{array}{l}\text { SAMP } \\
\text { LE 2 }\end{array}$ & $\begin{array}{l}\text { SAMPLE 3 (2 } \\
\text { penumpang) }\end{array}$ & $\begin{array}{l}\text { SAMPLE 4 (2 } \\
\text { penumpang) }\end{array}$ \\
\hline $\begin{array}{l}\text { PREPARATIO } \\
\text { N (detik) }\end{array}$ & 10 & 10 & 13 & 11 \\
$\begin{array}{l}\text { CHECK-IN } \\
\text { (detik) }\end{array}$ & 62 & 123 & 101 & 62 \\
$\begin{array}{l}\text { BAGGAGE } \\
\text { DROP (detik) }\end{array}$ & 0 & 0 & 122 & 119 \\
$\begin{array}{l}\text { TOTAL (detik) } \\
\text { TOTAL } \\
\text { (menit) }\end{array}$ & 72 & 133 & 236 & 192 \\
\hline \hline
\end{tabular}

\section{B. Data Sekunder}

Data yang didapatkan dari PT. Angkasa Pura I adalah data pergerakan penumpang 10 tahun terkahir, sedangkan jadwal penerbangan didapat dari website $\underline{\text { www.flightstats.com }}$

\section{Survei Karakteristik Penumpang}

Survey karakteristik penumpang diperlukan untuk mengetahui jumlah responden yang pernah menggunakan self check-in. Berikut hasil kuisioner yang telah dibuat penulis :

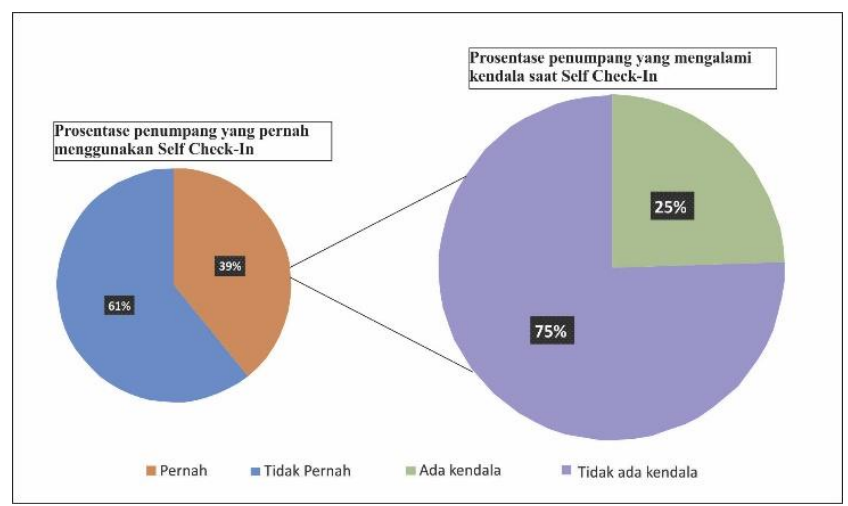

Gambar 3. Diagram Prosentase Hasil Kuisioner

\section{Analisis Antrian dengan Simulasi}

Untuk mengetahui panjang antrian pada suatu system antrian, dalam hal ini penulis menggunakan simulasi yang disesuaikan dengan kondisi eksisting. Pada kondisi eksisting maskapai Citilink (Terminal 1) terdapat 5 counter check-in dan 2 self check-in. Sedangkan kondisi eksisting maskapai AirAsia (Terminal 2) terdapat 3 counter check-in dan 4 self check-in. Berikut contoh pembagian penumpang tiap counter, dapat dilihat pada tabel 2 :

Tabel 2

Pembagian Penumpang tiap Counter Check-In

\begin{tabular}{rrr}
\hline \hline $\begin{array}{c}\text { Jumlah } \\
\text { Penumpang }\end{array}$ & $\begin{array}{c}\text { Jumlah penumpang } \\
\text { tiap counter }\end{array}$ & Waktu Datang \\
\hline 0 & 0 & $3: 00: 00 \mathrm{AM}$ \\
0 & 0 & $3: 10: 00 \mathrm{AM}$ \\
2 & 0 & $3: 20: 00 \mathrm{AM}$ \\
6 & 1 & $3: 30: 00 \mathrm{AM}$ \\
15 & 3 & $3: 40: 00 \mathrm{AM}$ \\
29 & 6 & $3: 50: 00 \mathrm{AM}$ \\
56 & 11 & $4: 00: 00 \mathrm{AM}$ \\
89 & 18 & $4: 10: 00 \mathrm{AM}$ \\
98 & 20 & $4: 20: 00 \mathrm{AM}$ \\
89 & 18 & $4: 30: 00 \mathrm{AM}$ \\
88 & 18 & $4: 40: 00 \mathrm{AM}$ \\
\hline \hline
\end{tabular}

Dapat dilihat pada table 2, jumlah penumpang didapat berdasarkan distribusi kedatangan menurut IATA. Sedangkan jumlah penumpang tiap counter didapat sebagai berikut : Jumlah penumpang tiap counter $=\frac{\text { Jumlah penumpang }}{\text { Jumlah } \text { counter }}$

Perhitungan panjang antrian dapat dilihat pada tabel 3 : Tabel 3

Contoh Simulasi Counter Check-In

\begin{tabular}{rcccc}
\hline \multicolumn{1}{c}{$\begin{array}{c}\text { COUNTER 1 } \\
\text { No. }\end{array}$} & $\begin{array}{c}\text { Waktu } \\
\text { Datang }\end{array}$ & $\begin{array}{c}\text { Waktu } \\
\text { Check-In }\end{array}$ & $\begin{array}{c}\text { Waktu } \\
\text { Keluar }\end{array}$ & Ket. \\
& & & & \\
\hline 1 & $3: 20: 00 \mathrm{AM}$ & $3: 20: 00 \mathrm{AM}$ & $3: 20: 33 \mathrm{AM}$ & $0: 00: 33$ \\
2 & $3: 30: 00 \mathrm{AM}$ & $3: 30: 00 \mathrm{AM}$ & $3: 30: 33 \mathrm{AM}$ & \\
3 & & $3: 30: 33 \mathrm{AM}$ & $3: 31: 06 \mathrm{AM}$ & \\
4 & $3: 40: 00 \mathrm{AM}$ & $3: 40: 00 \mathrm{AM}$ & $3: 40: 33 \mathrm{AM}$ & \\
6 & & $3: 41: 33 \mathrm{AM}$ & $3: 41: 06 \mathrm{AM}$ & \\
7 & & $3: 50: 00 \mathrm{AM}$ & $3: 50: 39 \mathrm{AM}$ & \\
8 & & $3: 50: 33 \mathrm{AM}$ & $3: 51: 06 \mathrm{AM}$ & \\
9 & & $3: 51: 06 \mathrm{AM}$ & $3: 51: 39 \mathrm{AM}$ & \\
10 & $3: 50: 00 \mathrm{AM}$ & $3: 51: 39 \mathrm{AM}$ & $3: 52: 12 \mathrm{AM}$ & \\
11 & & $3: 52: 12 \mathrm{AM}$ & $3: 52: 45 \mathrm{AM}$ & \\
12 & & $3: 52: 45 \mathrm{AM}$ & $3: 53: 18 \mathrm{AM}$ & \\
\hline
\end{tabular}

$\overline{\text { Sehingga didapat hasil perhitungan panjang antrian pada }}$ sebagai berikut :

Tabel 4

Hasil Rekapitulasi Panjang Antrian Check-In Konvensional

\begin{tabular}{lrrrrr}
\hline \hline \multirow{2}{*}{ AIRLINES } & \multicolumn{5}{c}{ COUNTER (penumpang) } \\
& 1 & 2 & 3 & 4 & 5 \\
\hline CITILINK & 33 & 33 & 33 & 32 & 32 \\
AIRASIA 1 & 40 & 40 & 39 & & \\
AIRASIA 2 & 28 & 28 & 27 & & \\
\hline \hline
\end{tabular}

Keterangan : - AirAsia 1 (Senin, Rabu, Jum'at, Minggu)

- AirAsia 2 (Selasa, Kamis, Sabtu)

- Skenario 1

$>$ penumpang menggunakan Check-In Konvensional

Tabel 5

Hasil Panjang Antrian pada Skenario 1 (Check-In Konvensional)

\begin{tabular}{lrrrrr}
\hline \hline \multirow{2}{*}{ AIRLINES } & \multicolumn{5}{c}{ COUNTER (penumpang) } \\
& 1 & 2 & 3 & 4 & 5 \\
\hline CITILINK & 20 & 20 & 20 & 20 & 19 \\
AIRASIA 1 & 25 & 24 & 24 & & \\
AIRASIA 2 & 17 & 17 & 17 & & \\
\hline \hline
\end{tabular}

$>\quad 39 \%$ penumpang menggunakan Self Check-In

Tabel 6

Hasil Panjang Antrian pada Skenario 1 (Self Check-In) COUNTER (penumpang)

\begin{tabular}{lrrrrr} 
AIRLINES & \multicolumn{5}{c}{ COUNTER (penumpang) } \\
& 1 & 2 & 3 & 4 & 5 \\
\hline CITILINK & 32 & 32 & & & \\
AIRASIA 1 & 12 & 12 & 11 & 11 & \\
AIRASIA 2 & - & - & - & - & \\
\hline \hline
\end{tabular}

- Skenario 2

> $86 \%$ penumpang menggunakan Check-In Konvensional 


\begin{tabular}{lrrrrr}
\multicolumn{7}{c}{ Tabel 7 } \\
Hasil Panjang Antrian pada Skenario 2 (Check-In Konvensional) \\
\hline \hline \multirow{2}{*}{ AIRLINES } & 1 & 2 & 3 & 4 & 5 \\
\hline CITILINK & 28 & 28 & 28 & 28 & 28 \\
AIRASIA 1 & 34 & 34 & 33 & & \\
AIRASIA 2 & 24 & 24 & 23 & \\
\hline \hline
\end{tabular}

$14 \%$ penumpang menggunakan Self Check-In

Hasil panjang antrian dapat dilihat pada Tabel 8

Tabel 8

Hasil Panjang Antrian pada Skenario 2 (Self Check-In)

\begin{tabular}{lrrrrr}
\hline \hline \multirow{2}{*}{ AIRLINES } & \multicolumn{5}{c}{ COUNTER (penumpang) } \\
& 1 & 2 & 3 & 4 & 5 \\
\hline CITILINK & 24 & 24 & & & \\
AIRASIA 1 & 8 & 8 & 8 & - \\
AIRASIA 2 & - & - & - & - \\
\hline \hline
\end{tabular}

Dengan hasil tersebut maka terdapat pengurangan panjang antrian di check-in konvensional, berikut hasilnya :

Tabel 9

Hasil Panjang Antrian Akibat Skenario 1 dan 2

\begin{tabular}{|c|c|c|c|c|c|c|}
\hline \multirow{5}{*}{$\begin{array}{c}\text { Akibat } \\
\text { Skenario } \\
1\end{array}$} & \multirow{2}{*}{ Airlines } & \multicolumn{5}{|c|}{ Counter (penumpang) } \\
\hline & & 1 & 2 & 3 & 4 & 5 \\
\hline & Citilink & 13 & 13 & 13 & 12 & 13 \\
\hline & AirAsia & 15 & 16 & 15 & & \\
\hline & AirAsia & 11 & 11 & \multicolumn{2}{|l|}{10} & \\
\hline \multicolumn{7}{|c|}{$\begin{array}{c}\text { Tabel } 10 \\
\text { Hasil Panjang Antrian Akibat Skenario } 1 \text { dan } 2 \text { (Lanjutan) } \\
\end{array}$} \\
\hline \multirow{5}{*}{$\begin{array}{c}\text { Akibat } \\
\text { Skenario } \\
2\end{array}$} & \multirow{2}{*}{ Airlines } & \multicolumn{4}{|c|}{ Counter (penumpang) } & \\
\hline & & 1 & 2 & 3 & 4 & 5 \\
\hline & Citilink & 5 & 5 & 5 & 4 & 4 \\
\hline & AirAsia & 6 & 6 & 6 & & \\
\hline & AirAsia & 4 & 4 & 4 & & \\
\hline
\end{tabular}

\section{E. Peramalan (Forecasting)}

1) Metode Prosentase Pertumbuhan

Perhitungan peramalan dengan metode prosentase pertumbuhan ini berdasarkan pada jumlah penumpang pada Bandara Juanda seperti pada rumus berikut :

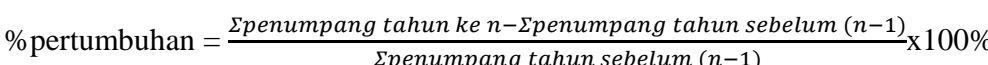

Maka, berdasarkan rumus diatas didapatkan rata-rata prosentase pertumbuhan untuk arus keberangkatan penumpang pada Bandara Juanda sebagai berikut :

$\%$ pertumbuhan rata $(\mathrm{i})=8 \%$

Tabel 11

Hasil Peralaman Jumlah Penumpang tiap Maskapai

\begin{tabular}{rrrrr}
\hline \hline \multirow{2}{*}{ Tahun } & $\begin{array}{c}\text { Tahun } \\
\text { ke- }\end{array}$ & Bandara & Citilink & AirAsia \\
\hline 2017 & 1 & $21,139,961$ & $2,424,240$ & 655,200 \\
2018 & 2 & $22,936,847$ & $2,630,299$ & 710,892 \\
2019 & 3 & $24,886,468$ & $2,853,873$ & 771,317 \\
\hline \hline
\end{tabular}

\begin{tabular}{lrrcc}
\hline \hline 2020 & 4 & $27,001,805$ & $3,096,451$ & 836,879 \\
2021 & 5 & $29,296,945$ & $3,359,648$ & 908,013 \\
2022 & 6 & $31,787,170$ & $3,645,216$ & 985,194 \\
2023 & 7 & $34,489,064$ & $3,955,058$ & $1,068,935$ \\
2024 & 8 & $37,420,617$ & $4,291,236$ & $1,159,793$ \\
2025 & 9 & $40,601,351$ & $4,655,989$ & $1,258,375$ \\
2026 & 10 & $44,052,445$ & $5,051,745$ & $1,365,337$ \\
\hline \hline
\end{tabular}

Tabel 12

Prosentase TPHP Berdasarkan Volume Tahunan menurut FAA

\begin{tabular}{ll}
\multicolumn{2}{c}{ Prosentase TPHP Berdasarkan Volume Tahunan menurut FAA } \\
\hline \hline Total Annual Passenger & TPHP as a\% of Annual Passenger \\
\hline 30 million and over & 0.035 \\
$20,000,000$ to $29,999,999$ & 0.040 \\
$10,000,000$ to $19,999,999$ & 0.045 \\
$1,000,000$ to $9,999,999$ & 0.050 \\
500,000 to 999,999 & 0.080 \\
100,000 to 499,999 & 0.130 \\
Under 100,000 & 0.200 \\
\hline \hline
\end{tabular}

Jadi, didapatkan prosentase TPHP pada Tabel 12 kemudian dikalikan dengan jumlah penumpang rencana pada Tabel 11, maka didapatkan jumlah penumpang maksimal per jam dan untuk tiap maskapai terdapat penambahan perkalian dengan dikalikan prosentase jumlah penumpang tiap maskapai sebagaimana pada tabel berikut :

Tabel 13 Perkiraan Peak Hour Passenger Pada Tahun ke 1 s/d 10

\begin{tabular}{|c|c|c|c|c|c|c|}
\hline \multirow{2}{*}{ Tahun } & \multirow{2}{*}{$\begin{array}{c}\text { Tahun } \\
\text { ke- }\end{array}$} & \multirow{2}{*}{$\begin{array}{c}\text { Jumlah } \\
\text { Penumpang } \\
\text { Bandara }\end{array}$} & \multirow{2}{*}{$\begin{array}{c}\text { TPHP as } \\
\text { a\% of } \\
\text { Annual } \\
\text { Passenger }\end{array}$} & \multicolumn{3}{|c|}{$\begin{array}{l}\text { Peak hour passenger } \\
\text { (penumpang/jam) }\end{array}$} \\
\hline & & & & Bandara & Citilink & AirAsia \\
\hline 2017 & 1 & $21,139,961$ & $0.040 \%$ & 8,456 & 970 & 262 \\
\hline 2018 & 2 & $22,936,847$ & $0.040 \%$ & 9,175 & 1,052 & 284 \\
\hline 2019 & 3 & $24,886,468$ & $0.040 \%$ & 9,955 & 1,142 & 309 \\
\hline 2020 & 4 & $27,001,805$ & $0.040 \%$ & 10,801 & 1,239 & 335 \\
\hline 2021 & 5 & $29,296,945$ & $0.040 \%$ & 11,719 & 1,344 & 363 \\
\hline 2022 & 6 & $31,787,170$ & $0.035 \%$ & 11,126 & 1,276 & 345 \\
\hline 2023 & 7 & $34,489,064$ & $0.035 \%$ & 12,071 & 1,384 & 374 \\
\hline 2024 & 8 & $37,420,617$ & $0.035 \%$ & 13,097 & 1,502 & 406 \\
\hline 2025 & 9 & $40,601,351$ & $0.035 \%$ & 14,210 & 1,630 & 440 \\
\hline 2026 & 10 & $44,052,445$ & $0.035 \%$ & 15,418 & 1,768 & 478 \\
\hline
\end{tabular}

Sehingga didapat peak hour penumpang pada tahun 2026, untuk maskapai Citilink adalah 1,768 penumpang/jam dan maskapai AirAsia adalah 478 penumpang/jam.

\section{2) Panjang Antrian 10 Tahun Mendatang}

Panjang antrian pada 10 tahun mendatang didapatkan dari perhitungan peak hour pada tahun 2026 dari Tabel 4.32. Setelah mendapatkan peak hour penumpang pada tahun 2026 , kemudian melakukan perhitungan panjang antrian jika jumlah counter check-in konvensional dan self check-in sesuai dengan kondisi sekarang yaitu untuk maskapai Citilink (Terminal 1) terdapat 5 counter check-in dan 2 self check-in. Sedangkan kondisi eksisting maskapai AirAsia (Terminal 2) terdapat 3 counter check-in dan 4 self check-in. Kemudian peak hour penumpang pada tahun 2026 dianalisi menggunakan simulasi untuk mendapatkan panjang antrian, terlebih dahulu peak hour 
tersebut dilakukan perubahan menjadi per 10 menit agar dapat disimulasikan. Berikut hasil rekapitulasi panjangng antrian 10 tahun mendatang.

Tabel 14

Hasil Rekapitulasi Panjang Antrian 10 Tahun Mendatang

\begin{tabular}{lrrrrr}
\hline \hline \multirow{2}{*}{ AIRLINES } & \multicolumn{5}{c}{ COUNTER (penumpang) } \\
& 1 & 2 & 3 & 4 & 5 \\
\hline CITILINK & 54 & 53 & 53 & 53 & 53 \\
AIRASIA & 25 & 25 & 24 & & \\
\hline \hline
\end{tabular}

3) Kebutuhan Counter Check-In 10 Tahun Mendatang

Kebutuhan counter check-in direncanakan jika kondisi eksisting tidak dapat menampung panjang antrian yang terjadi. Maka dengan hasil panjang antrian 10 tahun mendatang pada Tabel 4.14 , diperlukan kebutuhan counter check-in sebagai berikut :

$>$ Check-In Konvensional

Rekapitulasi hasil dapat dilihat pada Tabel 15

Tabel 15

Kebutuhan Counter Check-In Konvensional 10 Tahun Mendatang

\begin{tabular}{|c|c|c|c|c|c|c|}
\hline \multirow[b]{2}{*}{$\begin{array}{l}\text { AIRL } \\
\text { INES }\end{array}$} & \multirow[b]{2}{*}{$\begin{array}{c}\text { Tingkat } \\
\text { Kedatang } \\
\text { an }(\lambda) \\
\\
\text { (penumpa } \\
\text { ng/jam) }\end{array}$} & \multirow[b]{2}{*}{$\begin{array}{l}\text { Wakt } \\
\text { u } \\
\text { Pelay } \\
\text { anan } \\
\\
\text { (meni } \\
\text { t) }\end{array}$} & \multirow[b]{2}{*}{$\begin{array}{c}\text { Tingkat } \\
\text { Pelayana } \\
\mathrm{n}(\mu) \\
\\
\text { (penumpa } \\
\text { ng/jam) }\end{array}$} & \multicolumn{3}{|c|}{ Kebutuhan Counter } \\
\hline & & & & $\begin{array}{l}\text { Check- } \\
\text { In } \\
\text { Konven } \\
\text { sional }\end{array}$ & $\begin{array}{c}\text { Sken } \\
\text { ario } \\
1\end{array}$ & $\begin{array}{c}\text { Sken } \\
\text { ario } \\
2\end{array}$ \\
\hline $\begin{array}{l}\text { CITIL } \\
\text { INK }\end{array}$ & 1,768 & 1.49 & 40 & 44 & 27 & 38 \\
\hline $\begin{array}{c}\text { AIRA } \\
\text { SIA }\end{array}$ & 478 & 1.49 & 40 & 12 & 7 & 10 \\
\hline
\end{tabular}

$>$ Self Check-In

Tabel 16

Kebutuhan Self Check-In 10 Tahun Mendatang

\begin{tabular}{cccccc}
\hline \hline & $\begin{array}{c}\text { Tingkat } \\
\text { Kedatangan } \\
(\lambda)\end{array}$ & $\begin{array}{c}\text { Waktu } \\
\text { Pelayan } \\
\text { an } \\
\text { ES }\end{array}$ & $\begin{array}{c}\text { Tingkat } \\
\text { Pelayanan }(\mu\end{array}$ & $\begin{array}{c}\text { Kebutuhan } \\
\text { Counter }\end{array}$ \\
& $\begin{array}{c}\text { Kenumpang/ } \\
\text { jam) }\end{array}$ & (menit) & $\begin{array}{c}\text { (penumpang/ } \\
\text { jam) }\end{array}$ & $\begin{array}{c}\text { Skena } \\
\text { rio } 1\end{array}$ & $\begin{array}{c}\text { Skena } \\
\text { rio } 2\end{array}$ \\
\hline $\begin{array}{c}\text { CITILI } \\
\text { NK }\end{array}$ & 1,768 & 1.2 & 50 & 14 & 5 \\
$\begin{array}{c}\text { AIRASI } \\
\text { A }\end{array}$ & 478 & 1.2 & 50 & 4 & 1 \\
\hline \hline
\end{tabular}

Jadi, kebutuhan counter check-in konvensional 10 tahun mendatang untuk maskapai Citilink adalah 44 counter (tanpa self check-in), 27 counter (skenario 1), dan 38 counter (skenario 2), sedangkan untuk maskapai AirAsia adalah 12 counter (tanpa self check-in), 7 counter (skenario 1), dan 10 counter (skenario 2). Kebutuhan counter self check-in 10 tahun mendatang untuk maskapai Citilink adalah 14 counter (skenario 1), dan 5 counter (skenario 2), sedangkan maskapai AirAsia adalah 4 counter (skenario 1), dan 1 counter (skenario 2) sehingga maskapai AirAsia tidak memerlukan penambahan counter self check-in karena pada kondisi eksisting sudah memiliki 4 counter self check-in.

\section{KESIMPULAN DAN SARAN}

\section{A. Kesimpulan}

Adapun hal-hal yang dapat disimpulkan dari perbandingan kinerja pelayanan self check-in dan check-in konvensional dalam studi ini antara lain sebagai berikut:

1) Hasil distribusi kedatangan penumpang, yaitu :

- Maskapai Citilink

Dikarenakan jadwal penerbangan dalam 1(satu) minggu adalah sama, maka memiliki peak hour penumpang maskapai Citilink adalah 833 penumpang/jam pada pukul 5:50 AM.

- Maskapai AirAsia

AirAsia memiliki peak hour penumpang maksimum pada AirAsia 1 (Senin, Rabu, Jum'at, Minggu) pada pukul 4:10 AM dengan 487 penumpang/jam

2) Dari hasil perhitungan panjang antrian dengan menggunakan simulasi, yaitu :

- Tanpa Self Check-In

$>$ Maskapai Citilink

Memiliki panjang antrian maksimum yaitu 33 penumpang

$>$ Maskapai AirAsia 1 (Senin, Rabu, Jum'at, Minggu)

Memiliki panjang antrian maksimum yaitu 40 penumpang

$>$ Maskapai AirAsia 2 (Selasa, Kamis, Sabtu)

Memiliki panjang antrian maksimum yaitu 28 penumpang

- $\quad$ Skenario 1

$>61 \%$ penumpang menggunakan Check-In Konvensional

Memiliki panjang antrian maksimum sebesar :

- Citilink $=20$ penumpang

- $\quad$ AirAsia $1=25$ penumpang

- $\quad$ AirAsia $2=17$ penumpang

$39 \%$ penumpang menggunakan Self Check-In

Memiliki panjang antrian maksimum sebesar :

- $\quad$ Citilink = 32 penumpang

- $\quad$ AirAsia $1=12$ penumpang

- AirAsia 2 tidak ada antrian

- $\quad$ Skenario 2

$>$ 86\% penumpang menggunakan Check-In Konvensional

Memiliki panjang antrian maksimum sebesar :

- $\quad$ Citilink $=28$ penumpang

- AirAsia $1=34$ penumpang

- AirAsia $2=24$ penumpang

$14 \%$ penumpang menggunakan Self Check-In

Memiliki panjang antrian maksimum sebesar

- $\quad$ Citilink = 24 penumpang

- AirAsia $1=8$ penumpang

- AirAsia 2 tidak ada antrian

3) Dari hasil perhitungan simulasi panjang antrian tersebut, maka self check-in sangat efektif dalam mengurangi 
panjang antrian di check-in konvensional. Pada Skenario 1 dapat mengurangi antrian sebesar 13 penumpang untuk maskapai Citilink dan 15 penumpang untuk maskapai AirAsia, sedangkan pada Skenario 2 dapat mengurangi antrian sebesar 5 penumpang untuk maskapai Citilink dan 6 penumpang untuk maskapai AirAsia.

\section{B. Saran}

Adapun hal-hal yang diperlukan dalam studi ini antara lain :

1) Pada studi ini, memiliki kekurangan pada data survei karena tidak mendapatkan izin dari instansi terkait, maka pada penelitian selanjutnya diharapkan mendapatkan izin dari instansi terkait.

2) Metode peramalan yang digunakan pada studi ini hanya 2 metode yaitu metode Regresi Linear dan metode Prosentase Pertumbuhan. Maka pada penelitian selanjutnya diharapkan mengunakan metode peramalan yang lain, sehingga mendapatkan metode alternatif untuk menghasilkan peramalan yang lebih baik.
3) Memberikan saran kepada instansi terkait mengenai sosialisasi kepada pengguna moda transportasi pesawat terbang untuk meningkatkan penggunaan self check-in dan pengembangan self check-in dengan penambahan baggage drop, sehingga penumpang tidak perlu melakukan antrian di counter check-in untuk memasukkan bagasi.

\section{DAFTAR PUSTAKA}

[1] "https://play.google.com/store?hl=en," 2017. [Online]. Available: https://play.google.com/store?hl=en

[2] "http://www.flightstats.com," 2016. [Online]. Available: http://www.flightstats.com.

[3] I. A. T. Association, Airport Development Reference Manual 9th Edition.Montreal: Airports and Infrastructure Consultancy Services International Air Transport Association. 2004.

[4] S. et al Makridakis, Metode dan Aplikasi Peramalan, 2nd ed. Jakarta: Erlangga, 1988. 